\title{
EL SEÑOR Y EL MARGINADO: LA FAMILIA MORISCA OREJÓN Y LA RIVALIDAD DE LOS MAESTROS DE OBRAS CRISTIANOS
}

\author{
Aurelio García López \\ Universidad de Alcalá de Henares
}

\section{INTRODUCCIÓN}

El objetivo del presente trabajo es estudiar una familia mudéjar de maestros de obra que se convirtieron al cristianismo en 1502 y descubrir, hasta donde sea posible, su poder económico, su prestigio social y su comportamiento.

No pretendo hacer un amplio repaso sobre la arquitectura mudéjar, puesto que ya disponemos de estudios científicos muy detallados al respecto. Mi propósito es ver la relación que hubo entre los mudéjares de Guadalajara que trabajaron en numerosas obras en los siglos medievales y su posterior supervivencia o, mejor dicho, adaptación a las nuevas modas del arte del Renacimiento.

De la familia de obreros que estudio, llamada Orejón, disponemos de algunos datos con anterioridad a su conversión desde finales del siglo XV y su rastro se conserva hasta el inicio del siglo XVII. Los acontecimientos que protagonizan los Orejón se desarrollan durante aproximadamente setenta años, entre 1507 y $1574{ }^{1}$.

$\mathrm{La}$ investigación que presento en este estudio fue realizada con el objeto de ver lo más de cerca posible la forma en que se relaciona un grupo familiar morisco con unos nobles castellanos. Me interesa conocer con cierto detalle la actitud favorable hacia los moriscos de los duques del Infantado, nobles que tuvieron en los moriscos una considerable fuente de ingresos.

1 Esta familia se puede comparar a la de los Andado, que desempeñaron en Valladolid generación tras generación el oficio de maestros de obras y carpinteros, Gómez Renau, M., Comunidades marginadas en Valladolid. Mudéjares y moriscos. Valladolid, 1993, p. 72. 


\section{LOS MAESTROS DE OBRAS MORISCOS DE GUADALAJARA}

A partir de 1502 hubo algunos obreros moriscos activos en Guadalajara ${ }^{2}$. Este colectivo pronto contó con la competencia de los montañeses, que eran grandes trabajadores de la piedra. En los siglos xVI y XVII en Guadalajara tuvieron mucha implantación los albañiles, carpinteros y maestros de obras llegados desde las zonas montañosas de Santander, Burgos y Álava ${ }^{3}$. Eran expertos trabajadores de la piedra, que dejaron muestras muy representativas a lo largo y ancho de la provincia de Guadalajara durante el siglo XVI, entre ellos, edificios como los ayuntamientos de Tamajón y Fuentelencina. Al establecerse en Guadalajara para poder ejercer su oficio tenían que pasar un examen, realizado por los examinadores y veedores del oficio de albañiles y carpinte$\operatorname{ros}{ }^{4}$.

Entre las preferencias profesionales de los moriscos alcarreños destacan las de maestros de obras, albañiles y también la de fontaneros. La actividad de los fontaneros tuvo un amplio desarrollo ya desde el siglo $\mathrm{XV}$ y fue continudada por los moriscos convertidos de 1502. Muchos de ellos trabajaron en las obras hidráulicas del palacio del Infantado. Tanto Íñigo como Acacio y Diego de Orejón contrataron algunos trabajos de fontanería que realizaban los duques del Infantado en Guadalajara. El caso más representantivo que encontramos en Guadalajara fue López de Guadix, hijo de un maestro de obras morisco de Guadalajara, que trabajó como fontanero en el palacio del Prado para el rey Felipe II ${ }^{5}$. Las grandes obras de abastecimiento de agua por ingenieros y alcalleres mudéjares fueron las realizadas en Valladolid por el inge-

2 García López, A., Moriscos en tierras de Uceda y Guadalajara (1502-1610), Guadalajara, 1992, 69-70.

3 Muñoz Jiménez, J. M., «Maestros de obras montañeses en la provincia de Guadalajara durante los siglos XVI y XVII", Altamira, Santander, 1983-84, 195-210.

4 AHPGU, Protocolos Notariales, e.p. Francisco Aguilar, legajo 301, f. 1v, 4 de enero de 1610. En 1610, el montañés Francisco Sainz tenía que realizar el siguiente examen: contaba con veinticinco años al llegar a Guadalajara, por tanto persona de buena condición física y en busca de mejores condiciones económicas, según el examen, «al cual han hallado hábil y suficiente para hacer un cuarto de cada desde los cimientos hasta dejar el tejado, chimeneas y escalera de tapicería e pilar, e asentar puertas, e ventanas y labrar mampostería todo tosca y blanquear".

5 AHPGU, Protocolos Notariales, e.p. Miguel Pérez, legajo 78. Es una escritura de un traslado copiado de una carta otorgada por el escribano público de Madrid, Pedro de Esteban, en Madrid a 23 de julio de 1567, en la cual otorga poder a un hijo suyo para que cobre unos bienes de su padre en Guadalajara. 
niero Yuza, en $1497^{6}$. En Guadalajara fueron empleados por el primer duque del Infantado para la acometida de agua a su palacio en los últimos años del siglo Xv.

Tampoco debemos olvidar a los horneros, que eran los fabricantes de ladrillo y tejas; incluso muchos de ellos tenían de apellido Hornero, como los parientes de los Orejón en Alcalá de Henares.

\section{LA FAMILIA OREJÓN Y LA RIVALIDAD DE LOS MAESTROS DE OBRAS CRISTIANOS}

\subsection{Perfil biográfico y labor arquitectónica}

La familia Orejón fue una de las muchas familias de obreros mudéjares que se convirtieron al cristianismo en 1502, continuando con su oficio a lo largo del siglo XVI ${ }^{7}$. Era un clan familiar dedicado en su mayor parte a labores de albañilería, fontanería y carpintería que residía en Alcalá de Henares en las últimas décadas del siglo xv, instalándose parte de esa familia en Guadalajara en los primeros años del siglo XVI ${ }^{8}$. Desde su llegada a esta ciudad alcarreña son contratados como criados por los duques del Infantado, estando muy vinculados a la amplia familia de los Mendoza, y en particular al III, IV y V duque del Infantado. El primer representante de la familia Orejón que se instala en Guadalajara fue Íñigo de Orejón (1473-1542). Al llegar a la capital de la corte de los Mendoza, Íñigo comienza a trabajar en las obras del duque del Infantado ${ }^{9}$, don Diego Hurtado de Mendoza, quien le bautizará al cristianismo con el mismo nombre del conde de Saldaña, don Íñigo López de Mendoza, futuro cuarto duque del Infantado. Viene hasta aquí acompañado de su hermano Francisco. Aunque la familia Orejón no traslada a todos sus miembros a Guadalajara, sabemos que una sobrina de Íñigo permanece residiendo en Alcalá de Henares hacia 1539, y que 61-62.

${ }^{6}$ Gómez Renau, M., Comunidades marginales en Valladolid. Mudéjares y moriscos,

7 Sobre la familia morisca Orejón y otros maestros moriscos en Guadalajara, véase nuestro libro Moriscos en tierras de Uceda y Guadalajara (1502-1610), 69 a 75.

8 Ibidem, p. 71. Se plantea el interrogante de la posible relación que pudiera tener la familia Orejón con las familias de moriscos granadinos traídos por el cardenal Cisneros a Alcalá de Henares entre 1499-1500. 16 y ss.

9 Layna Serrano, F., Historia de Guadalajara y sus Mendoza, Guadalajara, 1943, v.II, 
dos de sus hijos se dedicaban a la construcción. Uno de ellos, Lope Hornero, era carpintero y el segundo, Diego Orejón, era albañil ${ }^{10}$.

La primera dificultad que encontramos, al iniciar nuestro estudio sobre Íñigo, es la de fijar el nombre de sus antepasados y el año exacto de su nacimiento y el de su aparición en Guadalajara. La única referencia con que contamos para precisar estos datos es un proceso inquisitorial que tuvo lugar en 1539 por la Inquisición de Toledo ${ }^{11}$.

Se desconoce el nombre de los padres de Íñigo, pero podría tener cierta relación con un alarife moro, Yuçuf Orejudo, que, en 1491, recibía un sueldo por su trabajo en las reformas realizadas en las casas arzobispales de Alcalá de Henares, obras ordenadas por el Cardenal Mendoza bajo la dirección del arquitecto Alberto de Carvajal ${ }^{12}$. Noticia importante y que nos puede permitir enlazar a la familia Orejón con los Mendoza, puesto que el Cardenal era natural de Guadalajara y hermano del primer duque del Infantado y tío del segundo duque. Hecho que debemos tener en cuenta, pues el cardenal Mendoza pudo recomendar a sus parientes a Íñigo, y que éste se trasladara desde Alcalá a Guadalajara. Incluso podríamos plantear otra hipótesis: que Íñigo trabajara con anterioridad en el palacio del cardenal Mendoza, en la colación de Santa María, en los últimos decenios del siglo xv, antes de hacerlo en las obras de los duques del Infantado. Recordemos que este ilustre personaje empleó a numerosos obreros moriscos en sus obras proyectadas en Guadalajara y Sigüenza.

La única noticia documental que tenemos del trabajo de estos obreros en el palacio de Santa María de la Fuente es que fueron empleados para la decoración interior yeseros moriscos procedentes de Calatayud ${ }^{13}$. La aristocracia solía emplear en sus obras a estos obreros; el

\footnotetext{
10 García López, A., op. cit., p. 71; Muñoz Jiménez, J. M., La arquitectura del manierismo en Guadalajara, Guadalajara, 1987, pp. 145-147, quien documenta a Diego de Orejón, vecino de Alcalá de Henares, trabajando en la torre de Chiloeches.

11 AHN, Inquisición, legajo 190/6.

12 San Román, F. de B., "Las obras y los arquitectos del Cardenal Mendoza", Archivo Español de Arte y Arqueología, 19 (1931), p. 159. En una partida de 1491 se menciona: "A Yuçuf Orejudo por faser cierta obra en las casas arçobispales de Alcalá, seis mil y setecientos y ochenta y dos maravedis y medio, los cuales les fueron dados por mandado de Alberto de Carabajal, maestro de obras del señor Cardenal.»

13 Pradillo y Esteban, P. J., «La desaparecida parroquia de San Gil de Guadalajara: estado de la cuestión y nuevas aportaciones", Wad-Al-Hayara, 21 (1994), 211-256. Aporta este autor un inmejorable estudio sobre esta parroquia con una dedicación especial a la decoración de sus yeserías mudéjares.
} 
caso más conocido es el del Cardenal Mendoza y el del duque de Medina Sidonia ${ }^{14}$.

\subsection{Los duques del Infantado y la familia Orejón}

Los primeros datos artísticos de la familia Orejón en Guadalajara se remontan a 1506 . Se trata de una noticia de un hermano de Íñigo de Orejón sobre su trabajo en el palacio de don Antonio de Mendoza. En el testamento del noble alcarreño se cita entre sus deudas una que dice: "a un hermano de Orejón, maestro de las obras del duque mi señor" por los trabajos que había realizado en sus obras. Posiblemente trabajó en algunos remates de las obras proyectadas por Lorenzo Trillo ${ }^{15}$, en el famoso palacio de don Antonio de Mendoza. Este hermano de Íñigo era Francisco de Orejón, que desde 1511 y hasta 1532 trabajaba como asalariado para el tercer y cuarto duque del Infantado en sus obras señoriales 16

Sobre la formación y orígenes de la familia Orejón en Alcalá de Henares sabemos poco ${ }^{17}$. Perteneciente a un clan familiar que traslada algunos miembros de su familia a Guadalajara, Íñigo había nacido en Alcalá de Henares, según declara en su interrogatorio inquisitorial. Desde su llegada a Guadalajara trabaja çomo un criado asalariado más de los duques del Infantado y en numerosas obras de importancia en la ciudad. Posiblemente se encargará en los primeros años del siglo xvi de rematar la finalización de las obras del palacio del Infantado. Íñigo, gracias al apoyo de la familia Mendoza, había conseguido realizar importantes obras en Guadalajara y ocupar en el concejo el puesto de alarife. Pero su importancia económica y la rivalidad de los restantes maestros de obras cristianos de la ciudad haría que fuera procesado por la Inqui-

\footnotetext{
14 Wagner, K., Regesto de documentos del archivo de Protocolos de Sevilla referentes a judios y moros, Sevilla, 1978, p. 9.

15 Arteaga y Falguera, C. de, La casa del Infantado cabeza de los Mendoza, tomo I, Madrid, 1940. Según este testamento hallado en la sección de Osuna, legajo 1737.

16 BN, MS. 11.142, f. 100r, recibe un salario de 18.000 maravedíes del mayordomo del duque, por las obras que realiza para el duque. Este Francisco de Orejón continúa trabajando en las obras del duque hasta 1532, año en que recibe de salario 12.000 maravedíes por su trabajo de tener "a su cargo de las casas de mi consejo" (BN, MS. 11142, f. 330r).

17 García López, A., op. cit., p. 71. No descartamos su origen granadino, llegados a Alcalá de Henares por la mediación de Cisneros.
} 
sición. Desde su llegada a Guadalajara se relaciona y trabaja conjuntamente con otros oficiales de origen morisco.

En 1507, Íñigo ya estaba trabajando para los duques del Infantado ${ }^{18}$. Desde su llegada a Guadalajara trabaja en importantes obras de la ciudad. Entre las noticias de los protocolos notariales aparece trabajando desde $1515^{19}$. Trabaja, en la mayor parte de los casos, asociado a otros maestros de obras moriscos de esta ciudad durante la década de los años veinte y treinta del siglo Xvi. Así pues, de origen alcalaíno, Iñigo aparece en Guadalajara por primera vez documentado en los protocolos notariales, en 1515. Desde entonces, realizará una amplia y meritoria labor arquitectónica. En 1517, aparece como maestro de obras del duque junto a los maestros Diego de Peñafiel y Diego de Santacruz. El sueldo que recibía Orejón ese año era: «por el reparo de la fuente y trastejar la casa" ${ }^{20}$. Observamos que además de trabajos de albañilería también realizaba obras de carpintería y fontanería ${ }^{21}$. En 1522 tuvo las primeras rivalidades con vecinos de Guadalajara. En marzo de ese año, otorga carta de procuración a favor del procurador general, Fernando de Ávalos, vecino de la villa de Valladolid, para que defienda sus pleitos en la chancillería castellana 22 .

Desde 1517 a 1532 continúa trabajando Íñigo con Diego de Santacruz para el duque del Infantado, recibiendo anualmente por su trabajo 20.000 maravedíes y 60 fanegas de trigo ${ }^{23}$.

Ínigo también llevó a cabo una labor constructiva particular importante para la ciudad. Desde 1517 comienza a contratar obras para particulares, trabajando junto a maestros de obras de origen morisco. Así, ese año, 1517, contrata la realización de unas casas para el señor Juan de Viana situadas en la colación de San Miguel, que tiene que construir junto a otros maestros de obras de origen morisco, llamados Pedro de Alfajarín y Diego de Guadix ${ }^{24}$. Se encargan de levantar un edificio con unas características propias de la arquitectura mudéjar, empleando materiales económicos como eran el tapial, ladrillo, cal, el pilar de cal, el

18 Ibidem, p. 71.

19 AHPGU, Protocolos Notariales, e.p. Alonso de Carranza, legajo 1, fol. 105r.

20 BN, MS. 11.142, f. 55r.

21 García López, A., op. cit., p. 71.

22 AHPGU, Protocolos Notariales, legajo 4, e.p. Alonso de Carranza, 29 de marzo de 1522 , f. $169 \mathrm{v}$.

23 BN, MSS. 11.142, f. 359r.

24 AHPGU, Protocolos Notariales, e.p. Alonso de Carranza, legajo 2, 23 de enero de 1517 , fols. $27 \mathrm{v}$ a $30 \mathrm{v}$. 
ladrillo y la madera. La obra se elevaba a la apreciable suma de 160.000 maravedíes, resaltando el empleo de la madera, tanto para el suelo del edificio como para los techos, donde los obreros moriscos eran grandes trabajadores. Íñigo era a la vez maestro de obras y carpintero.

En 1522 se le menciona otra vez como alarife del concejo, tasando unas casas propiedad de Rodrigo de Morales, mayordomo de Nuestra Señora de la Fuente, junto a maestre Juan ${ }^{25}$. Posteriormente trabaja con Miguel de Renales en la obra de la portada del convento de la Concepción franciscana ${ }^{26}$. En 1531 aparece junto al prestigioso Diego de Medina Medinilla ${ }^{27}$, mencionados como soladores y maestros de casas, a los que se encarga de tasar unas casas de la ciudad ${ }^{28}$ Además de trabajar en obras particulares para la baja nobleza alcarreña, es alarife del concejo de Guadalajara ${ }^{29}$.

Íñigo continúa trabajando para los Infantado hasta 1542 en que fallece y es sustituido por su hijo Acacio ${ }^{30}$. La labor emprendida por Íñigo fue continuada por su hijo Acacio, personaje multifacético, que a lo largo de su vida tuvo varias ocupaciones. Lo conocemos como supervisor de todas las obras que realizaba el duque del Infantado y se le menciona como carpintero, maestro de obras e incluso como recaudador de algunos impuestos señoriales de la casa del Infantado en

25 AHPGU, Protocolos Notariales, e.p. Alonso de Carranza, legajo 4, 24 de octubre de 1522 , fols. 448 y ss.

26 AHPGU, Protocolos Notariales, e.p. Alonso de Carranza, legajo 8, fols. 149-150; Muñoz Jiménez, J. M., op. cit., p. 77.

27 Ibidem, 131-133.

28 AHPGU, Protocolos Notariales, e.p. Alonso de Carranza, legajo 10, fol. 115v. Dice así la noticia: «En la noble ciudad de Guadalajara en casa de my el presente escribano a la colación de Santo Tome viernes ocho días del mes de septiembre, año del nascimiento de nuestro señor salvador Jesucristo de mil e quinientos e treinta e un años en presencia de mi Alonso de Carranza Escribano publico e testigos de yuso escriptis Iñigo Orejón e Diego de Medina soladores, maestros de casas e vecinos de esta dicha ciudad con juramento y en especial forma hicieron por que fueron a ver y vieron las casas que fueron de Francisco de Guadalajara e Leonor Díaz su mujer difuntos."

29 García López, A., op. cit., 71-74.

30 BN, MSS. 11.141, fol. 203v. "a los aderezos de Iñigo de Orejón maestro que fue de mis obras VII mil CCXV maravedíes que le montaron haber de su acostamiento de este dicho año hasta XIII de mayo del que falleció a razón de XX mil por año y diez y seis fanegas y cuatro celemines de trigo, a razón de sesenta fanegas por año, y a Acacio de Orejón su hijo que entre en su lugar la resta a cumplimiento de los dichos veinte mil maravedíes y sesenta fanegas». 
sus amplios territorios de la Alcarria, donde aparece como criado del duque ${ }^{31}$.

Entra al servicio del duque como maestro de obras en 1542 al fallecer su padre. En las cuentas de Acostamiento de los duques del Infantado, que se conservan hasta 1562, Acacio se mantiene hasta ese año en el mismo puesto. En 1545, como criado del duque, recibe el mismo sueldo que su padre, encargándose de: «aderezar a su costa las fuentes que vienen a su casa desde fuera de la ciudad hasta donde nacen» ${ }^{32}$.

$\mathrm{Al}$ año siguiente, 1546, además de aderezar las fuentes, realiza trabajos de albañilería y carpintería: «tiene a cargo hacer trastejar y reparar mis casas» ${ }^{33}$. Acacio continúa en la misma ocupación de maestro de obras del duque del Infantado, y en 1562, su sueldo había aumentado en 10.000 maravedíes, encargándose de los trabajos de fontanería de las fuentes de su señor y trastejar sus casas ${ }^{34}$. También en 1556 trabajaba Acacio como criado del marqués del Cenete, quejándose junto a nueve criados más de unas deudas que les debía su señor ${ }^{35}$. Ese mismo año, al redactar su testamento, menciona que su trabajo era al fiado, y prácticamente le debía dinero toda la aristocracia de la ciudad y otros vecinos.

Fue ante todo proveedor de materiales para otros obreros o para trabajos domésticos de los vecinos de la ciudad. Solía entregar los materiales al fiado.

También salió fuera de la ciudad de Guadalajara para trabajar o realizar encargos para la amplia familia Mendoza: en 1555, es nombrado por don Baltasar de la Cerda, uno de los herederos del estado de Pastrana, creado por su madre la condesa de Mélito para la tasación de la fortaleza de Pastrana. Esta tasación, Acacio la tiene que realizar junto a Alonso de Covarrubias y García de Cubillas, maestros de obras reales en los alcázares de Toledo y Segovia ${ }^{36}$. Aparece Acacio nuevamente

31 AHN, Osuna, legajo 3398 (e). Escritura otorgada en 30 de enero de 1574: es una carta de obligación donde Acacio de Orejón aparece como «mayordomo que he sido del Ylustrisimo señor duque del Ynfantado en el heredamiento de Fresno de Málaga».

32 BN, MSS. 11.141, fol. 235r

33 BN, MSS. 11.141, fol. 235r.

34 BN, MSS. 11.141, fol. $324 \mathrm{v}$.

35 AHPGU, Protocolos Notariales, e.p. Miguel Pérez, legajo 52, 12 de agosto de 1556. «Otorgan carta de poder a favor de Alonso de Torices, para que podáis haber e cobrar recesbir y recaudar todos los maravedíes que a cada uno de nos esta debiendo por librado de nuestro acostamiento."

36 AGS, Registro General del Sello (en adelante, RGS), 1555-I-29. 
como hombre de confianza de la nobleza alcarreña, a la vez que su prestigio va en aumento puesto que es tasador junto a grandes maestros de obras de su época ${ }^{37}$. Recordemos que ya su padre, Íñigo, había levantado una obra proyectada por Alonso de Covarrubias en Guadalajara.

Acacio es un verdadero inspector de todas las obras realizadas por el quinto duque del Infantado. Por poner un ejemplo, en las obras que ordena realizar don Íñigo, en su lugar de Málaga del Fresno, se menciona a Acacio como mayordomo del Fresno. En una obra de un tejado, Acacio reconoce los materiales que se van a emplear y se manifiesta en un contrato de cuatro vecinos de Yunquera con Acacio de Orejón: "Otro si que por que el dicho Acacio de Orejón está temeroso que la tierra para teja no parece tal como conviene de donde los suso dichos la tienen que hacer que quemen las tejas que quisieren primero para hacer la esperiencia e saliendo tales que a el dicho Orejón parezca que son buenas e bastantes e así dira si las han de hacer o no" ${ }^{38}$. Esta labor de inspección también la realizaba en trabajos escultóricos y de orfebrería que encargaban sus señores ${ }^{39}$.

La labor constructiva de Acacio ha sido del interés de varios investigadores en los últimos años, destacando por encima de todos los de Muñoz Jiménez ${ }^{40}$.

Tenemos noticias de la importante labor desarrollada por Acacio en la ciudad de Guadalajara hasta 1575 , donde es pagado por el concejo de la ciudad por las trazas de la denominada "fuente nueva", por lo que recibía doce ducados de los veinte en que había sido tasada ${ }^{41}$.

37 AGS, RGS, 1555-XII-14. Executoria del pleito que se a tratado entre don Baltasar de la Cerda con don Gaspar de la Cerda su hermano sobre los hedificios de la fortaleza de la villa de Pastrana. En la ejecutoria se inserta la tasación que hicieron de la fortaleza de Pastrana Alonso de Covarrubias, Acacio de Orejón y García de Cubillas; para su realización se presentaron los tres en Pastrana el 1 de marzo de 1555.

38 AHPGU, Protocolos Notariales, e.p. Juan de Medina, legajo 156, 6 de julio de 1572

39 García López, A., "Datos artísticos inéditos sobre el maestro de obras morisco Acacio de Orejón (1519-d. 1574)", Wad-Al-Hayara, 20 (1993) 265-290, esp. 271-274.

40 Muñoz Jiménez, J. M., op. cit., 140-143. Sin olvidar los siguientes trabajos: Layna Serrano, F., «La desdichada reforma del palacio del Infantado por el quinto duque del Infantado en el siglo XVI", Boletín de la Sociedad Española de Excursionistas, LXX, (1949), 1-138; Herrera Casado, A., "El arte del Humanismo mendocino en la Guadalajara del siglo XVI", Wad-Al-Hayara, 8 (1981), 345-384; García López, A., op. cit.

41 AMGU, Actas del Concejo, 16 de septiembre de 1575. "este día dyo petiçion Acacio de Orejón en que dyze que esta cibdad cometyo a los señores Pedro de Pastrana y Pedro Jimenez de Cañizares concertaren con él lo que se le avya de pasar de las condi- 
Estamos nuevamente ante el regateo y desconfianza de las autoridades municipales que emplean a los moriscos para sus obras y posteriormente maniobran para reducir sus gastos. Es un caso más de marginación: los regidores son rígidos ante las clases marginadas a las que pueden incluso amenazar, pero posteriormente derrochan el dinero en fiestas y en una nefasta actuación marcada por sus intereses personales.

Este encargo del concejo de Guadalajara es la última obra conocida de Acacio, estando ya muy cercana su muerte. Había pasado tras de sí una incansable labor artística siempre fiel a los mandatos de sus señores y protectores que confiaron más en él como inspector que como trazador.

Tampoco debemos olvidar a otro miembro de esta familia, Diego de Orejón, maestro de obras, hermano de Acacio, quien se formó artísticamente, al igual que Acacio, al lado de su padre Íñigo. En 1559, Diego de Orejón ya trabajaba independiente de su hermano y ese año había realizado algunos trabajos de fontanería en la fuente principal de la ciudad y el repartimiento adecuado del agua por todo el casco urbano. Era un contrato con la ciudad de Guadalajara pero no estuvo muy afortunado y tuvo que pasar varios días en la cárcel. En la sesión del concejo de 19 de mayo de 1559, informaba el licenciado Cristóbal de Priego, por entonces corregidor de Guadalajara:

"Dio noticia el señor corregidor como tyene preso a Diego de Orejón por que tenya hecho en el aqueducto del agua que va a Santa Clara el agujero mayor de lo que puede estar según paso ante Francisco de Buencía, escribano para que probea lo que sobre ello convenga" 42 .

Diego, por su juventud y poca experiencia en su obra de fontanería, no se había ajustado a las condiciones de su contrato y su obra no había sido del agrado de los regidores, que informaron al corregidor para que procesara a Diego de Orejón. Tras una consulta con el letrado de la ciudad, nuestro joven Diego es castigado severamente junto a otras personas:

\footnotetext{
ciones que yzo de la fuente nueva y de la maestrya de besytar las y que se reservyo con ellos a los que se le dyeren veyente ducados e los dichos señores comysarios dieron relaçion de lo suso dicho y tratato sobre ello se acordo se le den e paguen al dicho Acacio de Orejón por la razon suso dicha doze ducados los quales se le den del arco de vyenes comunes con solo se de este acuerdo.....

42 AMGU, Actas del concejo, 19 de mayo de 1559, fol. 47r.
} 
Arbol genealógico familiar Orejón

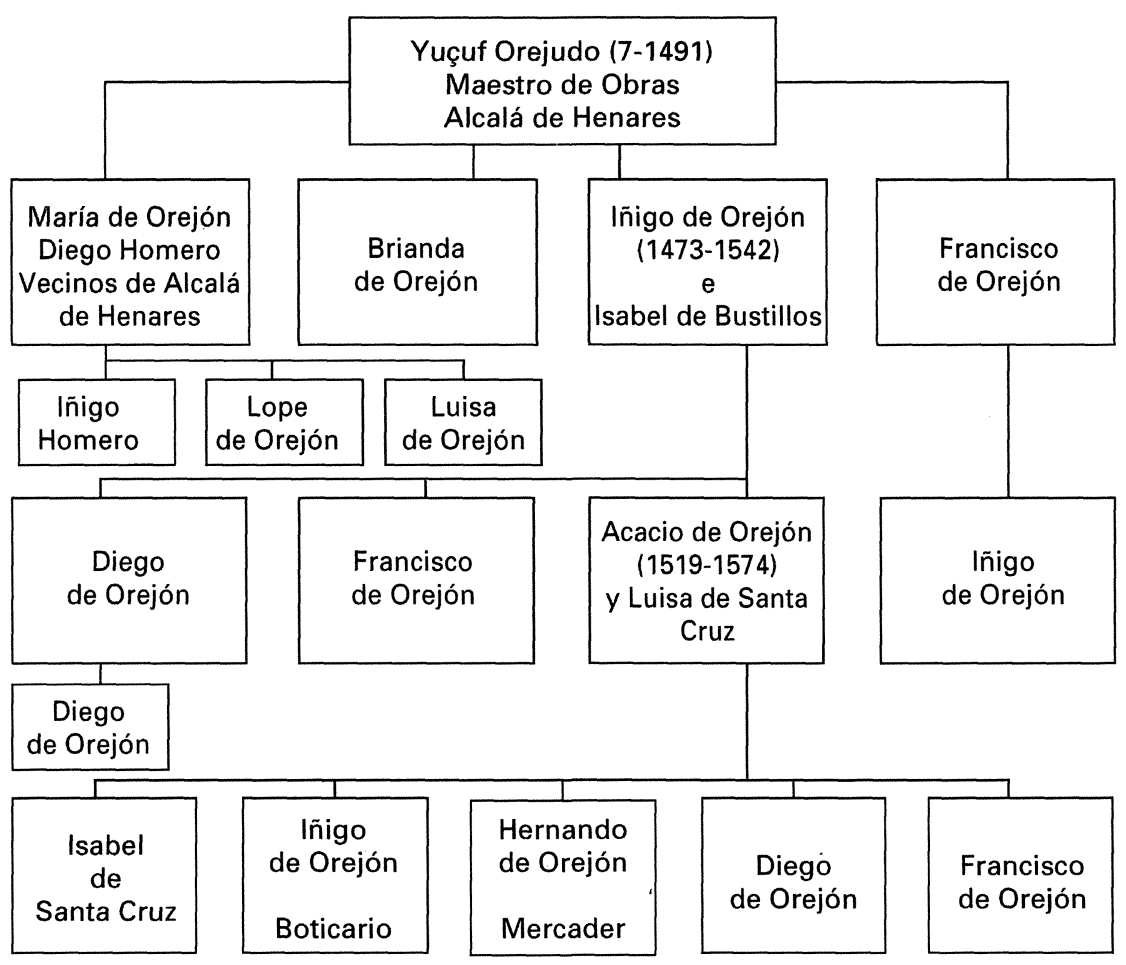

"que se entendieron en encañar el agua para el monasterio de Santa Clara abian hecho çierta falsedad o delyto de que están acusados» 43 .

Desconozco como finalizó este proceso. Pero posteriormente fue empleado de nuevo por el concejo también para obras de fontanería. La amplia laguna de actas municipales de 1560 a 1571 nos impide conocerlo con detalle.

Sí podemos decir que por esta circunstancia Diego de Orejón pudo verse obligado a abandonar la ciudad, a pesar de realizar en 1564 la cimentación de los conventos de la Concepción ${ }^{44}$. Y en marzo de 1568 , Diego de Orejón, maestro de obras, vecino de Madrid, recibe autorización real para poder llevar desde Guadalajara a Madrid cierto trigo

43 AMGU, Actas del concejo, 24 de mayo de 1559.

44 AHN, Csuna, legajo 3389 (c), fols. 304r a 306v. Donde su hermano Acacio es su fiador. 
para «la provisión de su casa y criados en Madrid» que su hermano Acacio de Orejón le proporcionaba desde Guadalajara ${ }^{45}$. Unos meses después es contratado por el concejo de Guadalajara, puesto que desde allí se traslada a esta ciudad para llevar a cabo unos trabajos de fontanería en una fuente:

"que a causa del estrajo que había hecho una gran avenida en la fuente principal de ella que hera una de las ynsignias de estos reynos y su tierra y de la gran necesidad que tenía del reparo se les mandaré dar licencia para repartir... la habían hecho los dichos alarifes y otros maestros y Diego de Orejón, fontanero, vecino de esta corte» ${ }^{46}$.

En la Corte de los Austrias fue empleado en ocasiones como alarife por el concejo de Madrid donde pasó Diego de Orejón sus últimos años.

\subsection{La relación profesional con otros maestros de obras de la ciudad}

Sin duda la influencia de la familia Mendoza en Guadalajara y su apoyo incondicional hacia Íñigo de Orejón, le proporcionaron el cargo de alarife del concejo. Puesto aceptado por los restantes oficiales de Guadalajara, pero del que pronto fue derribado por ser converso. ¿Cuál fue, entonces, el origen de tal discriminación? Si los cargos más importantes del concejo estaban reservados a los hidalgos ¿por qué Íñigo fue nombrado alarife? ${ }^{47}$. Los duques del Infantado hicieron valer su poder y alzaron a Íñigo a un cargo concejil. Otros conversos que asomaron en el concejo en el siglo XVI fueron igualmente derribados y sacados de él a través de la denuncia inquisitorial ${ }^{48}$. En este caso, no son los representantes del concejo los que acusan a Íñigo, sino sus propios compañeros de trabajo. ¿Por qué esa actitud? Se debió a acontecimientos fortuitos y del azar que no esperaba Ínigo en absolu-

45 AGS, RGS (Registro General del Sello), 13 de marzo de 1568.

46 AGS, RGS, 21 de octubre de 1568.

47 Guillén, C., "Un padrón de conversos sevillanos (1510)", Bulletin Hispanique, 65 (1963), p. 50. Los conversos tenían prohibido desde 1501 ocupar puestos públicos.

48 Lorenzo Cardoso, P. L., «Esplendor y decadencia de las oligarquías conversas de Cuenca y Guadalajara (siglos XV y XVI)", Hispania, LIV/1, 186 (1994), 53-94. 
to ${ }^{49}$. Fue la importancia económica de Íñigo y su rivalidad con los restantes obreros cristianos lo que haría que fuera procesado por la Inquisición. En 1538, al ser interrogado, declaraba así, refiriéndose a varios maestros de obras de la ciudad:

"de mi oficio que me tienen gran enemistad, por que así el duque mi señor como otros muchos caballeros y gente noble de la dicha ciudad, hace de mi mucha confianza poniéndome en sus obras, así para que las haga como para tasar las que otros hacen, y otras cosas de mi arte, e como alarife que soy nombrado por la dicha ciudad, los suso dichos sospechosos que yo les daño en sus oficios y envidiosos de los que en mí se confían por que los parece que si yo fuese muerto se confiaría de ellos, y contratarían en mi lugar» ${ }^{50}$.

Es procesado mientras realiza unas obras en el patio de don Alonso de la Plazuela, acusado por unos obreros cristianos a quienes tenía que supervisar y vigilar sus trabajos. Pidió justicia Iñigo al Inquisidor General de Toledo y de forma inmediata intervino su protector, el duque del Infantado. En pocos meses, Íñigo volvió de nuevo a Guadalajara. Su arraigo a las costumbres musulmanas le supuso una fuerte sanción económica y la realización de unos actos de penitencia en la capital alcarreña.

\subsection{Otras actividades económicas complementarias a la construcción}

No tenemos noticias de si Î́nigo de Orejón desempeñó otra actividad económica, además de ser maestro de las obras de los duques del Infantado. En el caso de Acacio, va aumentando su patrimonio a través de su forma de negociar. Ante todo es un gran comerciante con la venta de productos al fiado, tanto de materiales para la construcción (cal, ladrillo, madera), como de textiles e incluso trigo. Vende sus productos al fiado, tanto a otros albañiles de la ciudad como a los grandes señores. En su testamento, comprobamos que le debía dinero la totalidad de la aristocracia de la ciudad de Guadalajara (duques del Infantado,

49 Contreras, J., Sotos contra Riquelmes. Regidores, inquisidores y criptojudios, Madrid, 1991, p. 29. Es un caso similar al ocurrido con las oligarquías conversas de Murcia.

50 García López, A., op. cit., p. 194. Documento del AHN, Inquisición, legajo 196, expediente 10 . 
marqueses del Cenete, Montesclaros y Cogolludo) ${ }^{51}$. Revisando el testamento de Acacio, comprobamos cómo trabaja en muchas de sus obras al fiado, y prestaba materiales a otros obreros de la ciudad. Otra de las actividades económicas desarrollada por Acacio fue la venta de productos textiles, que posiblemente realizaban su mujer y criados de forma doméstica ${ }^{52}$, tradición de la comunidad mudéjar de Guadalajara que se remonta al siglo xiv. Aunque no debía de ser una dedicación especial, en 1558 Acacio realiza un total de 13 pequeñas ventas de teji$\operatorname{dos} 53$.

\subsection{La parentela morisca. El clan familiar Orejón}

Los mudéjares convertidos al cristianismo en el centro peninsular en 1502 no sufrieron las atrocidades de los de Andalucía Oriental ${ }^{54}$. Tras una conversión pacífica, nuestra familia de maestros de obras centrarían su vida rutinaria con el fin de ir alcanzando mayores caudales y prestigio día a día. Su fama de trabajadores les hizo que fueran contratados por el tercer duque del Infantado, pasando a ser sus maestros de obras en Guadalajara. Desde los primeros años del despertar del siglo XVI trabajan en las obras de los nobles alcarreños. A renglón seguido, Ínigo es nombrado alarife del concejo, trabajando por esos años en obras trazadas por el prestigioso Alonso de Covarrubias. Pero su finalidad primordial de vigilancia y control de todas las obras que realizaba la familia Mendoza produjo el roce y choque con otros artistas de Guadalajara. La carrera vertiginosa y en alza de Íñigo tropieza con un problema cotidiano de la época, la limpieza de sangre ${ }^{55}$. Se trata de un converso recién convertido de musulmán a cristiano. Si Acacio continúa con la labor desarrollada por su padre, no se introduce en el con-

51 AHPGU, Protocolos Notariales, e.p. Melchor de la Torre, 29 de noviembre 1555. Testamento Acacio de Orejón.

52 Pérez Villaamil, A., "Aumentos a la relación de Guadalajara", Memorial Histórico Español, LI, (1908), p. 252. Desde 1347 existen referencias documentales de la realización de forma doméstica de tejidos por los moros de la ciudad de Guadalajara.

53 AHPGU, Protocolos Notariales, e.p. Miguel Pérez, legajo 74. Escrituras otorgadas en: 20 y 29 de noviembre, y 1, 2, 3, 4, 7 y 19 de diciembre.

54 Ladero Quesada, M. A., Los mudéjares de Castilla en tiempo de Isabel I, Valladolid, 1969, 15-26.

55 Contreras, J., Sotos contra Riquelmes, p. 25. Indica que el problema de la limpieza de sangre siempre supuso para los conversos de Murcia y Lorca un hilo que podía "desatar trágicas pasiones". 
cejo, ya que sabía por experiencia lo que había ocurrido con su padre y evita por todos sus medios ser nombrado alarife, manteniéndose bajo la protección de su señor y al margen de los problemas cotidianos de los restantes maestros de obras cristianos con los que incluso colabora en algunas obras.

Acacio renuncia al ascenso social que podía conseguir por su prestigio y dinero; había conocido con su propio padre «la ofensiva de la limpieza de sangrem. Desde entonces intentará introducirse en la sociedad cristiana poco a poco. A sus hijos los sigue casando, como hacía su padre, con descendientes de moriscos; no los mezcla con ningún cristiano, pero él se introduce en la cofradía del Santísimo Sacramento ${ }^{56}$. En otras ciudades hubo también moriscos que se introdujeron en cofradías ${ }^{57}$. Es un paso más de integración, pero manteniéndose al margen de las aspiraciones de los cristianos.

¿Cuál era el concepto de familia de los Orejón? El concepto de familia es configurado a la vez por el principio de austeridad, encarnado en el cabeza de familia, el marido ${ }^{58}$. En nuestro caso, Íñigo y posteriormente su hijo, Acacio, son quienes dirigen a todo el grupo familiar que se mueve a su alrededor. Estamos ante una estructura familiar de carácter patriarcal. Para los Orejón la familia no es sólo una comunidad humana de personas, sino que es una comunidad de bienes, un grupo económico y de protección, que sirve para mantenerse y promocionarse a la vez. Acacio protegió y fue curador de varios menores de origen morisco que se encontraban desamparados, como fueron los menores de Gabriel Bustillo, maestro de obras procesado por la Inquisición. Aunque se trate de una relación de solidaridad derivada del parentesco, puesto que Gabriel de Bustillo era su tío por parte de madre. En el caso de la familia Orejón, fue su origen converso y la marginación del resto de la sociedad, lo que les hizo mantenerse unidos entre sí, con apoyo mutuo en sus obras y con enlaces matrimoniales de su mismo gremio, con hijos de otros maestros de obras. Los matrimonios de Íñigo y de

56 AHPGU, Protocolos Notariales, e.p. Diego de la Torre, legajo 27, 29 de noviembre de 1555. En su testamento ordena Acacio de Orejón: «me acompañen al dicho mi enterramiento el cabildo de las hachas del Santísimo Sacramento de dicha Iglesia de que soy cofrade".

57 Ibáñez Pérez, A., Burgos y los burgaleses en el siglo XVI, Burgos, 1990, p. 258. Muchos moriscos fueron cofrades en la Hermandad de Santiago, que estaba formada por el gremio de albañiles y carpinteros de la ciudad de Burgos.

58 Caro Baroja, J., "Sobre el concepto de casa, familia y costumbres", Saioak, Revista de Estudios Vascos, 2, San Sebastián (1978), 3-13. 
sus hijos Acacio y Diego son con mujeres de origen morisco. Íñigo de Orejón estuvo casado con Isabel de Bustillo, hija de Gabriel de Bustillo, albañil, morisco de Guadalajara y de su enlace matrimonial tuvo tres hijos; dos de ellos fueron maestros de obras, Acacio y Diego, que continuaron el oficio de su padre, siendo oficiales de cierta consideración. Curiosamente, ambos se casaron con dos hermanas, Luisa de Santacruz, mujer de Acacio, y María de Luna, mujer de Diego ${ }^{59}$. Los enlaces entre las familias conversas Orejón y Luna todavía se producían en los primeros años del siglo xvII: en 1618 estaba casado Juan Acacio de Orejón con Isabel de Luna, vecinos de Guadalajara 60.

Acacio estaba casado con Luisa de Santacruz, con la que tuvo cinco hijos (Juan, Íñigo, Francisco, Hernando e Isabel). Unicamente uno de ellos, Juan, se dedicó a la albañilería, pero tuvo que ser una figura de segundo orden, pues no hemos podido encontrarle trabajando en ninguna obra de importancia en esta ciudad, mientras que Hernando estuvo muy vinculado a la familia Mendoza, al igual que su padre ${ }^{61}$.

Un miembro de la familia Orejón que había quedado en Alcalá de Henares, Diego de Orejón, al igual que los otros miembros de esta familia en Guadalajara, también contraen matrimonio con miembros de la misma comunidad morisca. Pues Diego de Orejón murió en 1557, casado con Gracia de Santacruz, hija de Hernando Sillero, y de Francisca de Villarroel. Curiosamente, Gracia de Santacruz era hija de otro maestro de obras morisco, Hernando de Sillero, quien trabajó junto a Diego de Orejón. En su matrimonio tuvieron tres hijos, el bachiller Íñigo Hornero, Lope de Orejón y Luisa de Orejón ${ }^{62}$.

Estamos ante una familia que lleva a cabo claros enlaces matrimoniales con otros miembros de origen morisco de su misma localidad y mismo oficio ${ }^{63}$. Se mantiene una relación familiar y artística. Se obser-

59 AHPGU, Protocolos Notariales, e.p. Melchor de la Torre, legajo, 29. Testamento de Luisa de Santa Cruz, mujer de Acacio de Orejón, otorgado en 25 de abril de 1558.

${ }^{60}$ AHPGU, Protocolos Notariales, e.p. Simón Hurtado, legajo 284, 6 de enero de 1618.

61 AHN, Osuna, legajo 3398(e), e.p. Diego de Cisneros, fol. 301r.

62 AHPGU, Protocolos Notariales, e.p. Diego Pérez, legajo 48, 9 de enero de 1557. Los herederos de Diego de Orejón reclaman una casa que su padre tenía en Guadalajara. 1618.

63 AHPGU, Protocolos Notariales, e.p. Rodrigo Gumin legajo 284, 6 de enero de 
va claramente el caso de una familia con una estructura nuclear y residencia neolocal, lo que que era muy propio de los núcleos urbanos ${ }^{64}$.

¿Por qué razón no se promocionó más socialmente la familia Orejón? Parece ser que estaba concebida una estrategia en el cabeza familiar en la forma de actuar de la familia y distribuir equitativamente sus bienes. La transmisión del patrimonio estaba en plena libertad del padre, pero con un reparto equitativo entre sus hijos ${ }^{65}$.

En el clan Orejón, solamente uno de sus hijos recibe estudios universitarios. Íñigo había proporcionado estudios a su hijo Francisco de Orejón que, en 1538, era Bachiller, y que emigró a Indias a ejercer su oficio ${ }^{66}$, a pesar de tenerlo prohibido ${ }^{67}$. Posteriormente, Acacio sigue el ejemplo de su padre, dando a uno de sus hijos, Íñigo, estudios universitarios en Alcalá de Henares y Madrid, para aprender su oficio de boticario ${ }^{68}$. Ínigo de Orejón, boticario, había estudiado su oficio desde 1557 a 1564, en las universidades de Alcalá de Henares y Valencia, gastándose su padre, Acacio, un total de 63.592 maravedíes, por sus estudios, aprendizaje y adquisición de libros y medicamentos para su botica ${ }^{69}$. En 1576 se menciona a un licenciado Orejón, hijo de Acacio de Orejón, que residía en Guadalajara ${ }^{70}$. Otro caso de promoción social de los hijos de Acacio fue el matrimonio de su hija, Isabel de Santa-

${ }^{64}$ Chacón Jiménez, F., "Notas para el estudio de la familia en la región de Murcia durante el Antiguo Régimen", Historia Social de la familia en España, Alicante, (1990), 101-136.

65 Montojo Montojo, V., El siglo de Oro en Cartagena (1480-1640): Evolución económica y social de una ciudad portuaria del sureste español y su comarca, Murcia, 1993, 96113.

66 AHPG, Protocolos Notariales, e.p. Melchor de la Torre, legajo 27, 29 de noviembre de 1555. En 1555, Ínigo se encontraba en las Indias, puesto que su hermano Acacio le administraba unas casas que tenía en la colación de Santa María.

67 Ricard, R., "Indiens et morisques", Etudes et documents pour l'histoire missionaire de l'Espagne et du Portugal, Lovaina, 1931, 209-219; Cardaillac, L, "Le probleme morisque en Amérique", Mélanges de la Casa de Velázquez, XII (1976), 283-306; Garrido Aranda, A., Moriscos e indios. Precedentes hispánicos de la evangelización en Méjico, Méjico, 1980; Mechoulan, H., Le sang de l'autre ou l'homme de Dieu: Indiens, juifs et morisques au siécle d'or. París, 1977; García-Arenal, M., «Moriscos e indios. Para un estudio comparado de métodos de conquista y evangelización", Chronica Nova, 20 (1992), 153175.

68 AHPGU, Protocolos Notariales, e.p. Gaspar Hurtado, legajo 4.071/1, 23 de abril de 1568.

69 García López, A., "Los boticarios de Guadalajara en el siglo xvı, según un inventario de medicamentos de 1588", Cuadernos de Etnología de Guadalajara, 25 (1993), p. 351.

70 AGS, RGS, 1576-I-26. Querella de Acacio de Orejón y el licenciado Orejón, su hijo, contra una sentencia pronunciada por el corregidor de Guadalajara contra ellos. 
cruz, a quien casó con el licenciado Diego de Medina, médico de Guadalajara, para cuyo enlace matrimonial, Acacio le había proporcionado 1.000 ducados ${ }^{71}$. En el testamento de Acacio, comprobamos la transmisión patrimonial de sus bienes entre sus hijos, y que había ya adelantado parte de su herencia a su hija como dote matrimonial.

Acacio alcanzó un gran prestigio entre los restantes miembros de la comunidad morisca de Guadalajara. Fue elegido como procurador de algunos menores de la ciudad ${ }^{72}$. También, en 1556 , se encarga de los menores del albañil, morisco, Gabriel de Bustillo, difunto ${ }^{73}$ y a quienes estaba protegiendo con importantes sumas de dinero, puesto que Gabriel de Bustillo había sido procesado por el Tribunal de la Inquisición de Toledo y su patrimonio confiscado por el Santo Oficio ${ }^{74}$. En otras ocasiones es nombrado fiador y procurador de criados de origen morisco de los duques del Infantado 75 .

La ayuda mutua entre la comunidad morisca de Guadalajara se aprecia en la demanda que alcanzó Acacio, al ser el personaje más prestigioso de esa comunidad; muchos de los conversos recurrirán a su poder moral y económico en cualquier momento de dificultad.

\section{Conclusión}

Resumiendo los datos disponibles sobre la familia Orejón, podemos sacar algunas conclusiones. Los maestros de obras moriscos for-

71 AHPGU, Protocolos Notariales, e.p. Diego Pérez, legajo 80, 26 de junio de 1560.

72 AHPGU, Protocolos Notariales, e.p. Miguel Pérez, legajo 75, 31 de diciembre de 1567. Se hace cargo de la tutela del menor Iñigo de Zarate.

73 AHPGU, Protocolos Notariales, e.p. Melchor de la Torre, legajo 28, 16 de marzo 1556. En otra escritura otorgada ante Blas Carrillo, 10 de agosto de 1565, al contraer matrimonio Inés de Bustillo con Bartolomé de Morales, declaraban sobre la procuración que había realizado Acacio de Orejón: "Y en un capítulo de la dicha cuenta vos el dicho Acacio de Orjeón declarantes que se debían a Gabriel de Bustillo nuestro padre en el reino de Valencia treinta coronas por obligación que de ellos avra e que de ello cobrastes tan solamente tres mil e novecientos e diez maravedíes e que los demás no los podistes cobrar ni cobrastes por no enviar una persona a ello» (AHPGU, Protocolos Notariales, e.p. Blas Carrillo, legajo 60, 10 de agosto de 1565).

74 AHPGU, Protocolos Notariales, e.p. Melchor de la Torre, legajo 27, 29 de noviembre de 1555 .

75 AHPGU, Protocolos Notariales, e.p. Miguel Pérez, legajo 78, 14 de febrero de 1567. Es una carta de poder otorgada por Diego Martínez, criado del duque del Infantado, a favor de Acacio de Orejón. 
maban una comunidad muy fuerte y arraigada en España y sus enlaces matrimoniales eran con otros miembros de la misma comunidad.

Trabajan en cuadrillas integradas por miembros convertidos en 1502 , que se protegen asimismo contra los restantes obreros cristianos de la ciudad. Saben adaptarse a los nuevos estilos arquitectónicos del siglo XVI, abandonando el uso del ladrillo y la madera por el de la piedra sillar.

Si bien nuestra familia Orejón tuvo una mayor relación con los obreros cristianos de la ciudad, nunca perdió sus lazos asociativos con los restantes miembros de su comunidad. La solidaridad étnica era una ventaja económica que les podía ayudar a ser más eficaces y competitivos en su oficio.

La cohesión solidaria familiar garantizó la trayectoria ascendente y el incremento de su patrimonio. El prestigio alcanzado por los Orejón se consiguió mediante la capacidad de trabajo y negociación.

Una investigación rigurosa sobre la parentela familiar morisca ha de enfocarse desde la perspectiva de sus intereses profesionales y los vínculos de la estructura del poder ciudadano, teniendo en cuenta las circunstancias del azar que son imprevisibles entre los grupos conversos, que amenazan continuamente su ascenso social.

La familia Orejón, a pesar de tener un alto grado de consideración en la ciudad como protegidos de los duques del Infantado, verá cómo sus esfuerzos por integrarse dentro de la sociedad cristiana y ascender socialmente son impedidos, y tras un intento fallido de Iñigo, Acacio decidió mantenerse al margen. Siguen manteniendo estrechos lazos de clientelismo entre varias familias moriscas convertidas al cristianismo a partir de 1502, relacionándose con miembros de su misma comunidad y viviendo en el mismo barrio. El clan Orejón admitió el casamiento entre primos hermanos, y puesto que la mayoría de sus miembros vivía en Guadalajara y Alcalá, estaban muy unidos entre sí. Su aspiración primordial es consolidar un amplio patrimonio. Para ello, además de sus trabajos de construcción, mantienen otros negocios de venta de materiales constructivos, administración y tutela de menores y sus mujeres realizan trabajos textiles domésticos. Todo ello con un único fin, el enriquecimiento, desde el cual se puede aspirar a borrar su origen converso. 


\title{
RESUMEN
}

Dentro del indudable atractivo que provoca hoy día el estudio del siglo XVI, queremos ofrecer la visión de un trabajo local, realizado bajo la óptica de una familia de maestros de obra moriscos: la familia Orejón.

Pretendemos dar a conocer la protección de la nobleza a sus criados moriscos que encuentran gran número de obstáculos para realizar su trabajo diario por parte de los cristianos.

En el presente trabajo, dejando al margen las cuestiones artísticas, damos una aproximación sobre la formación de una red de parentesco y su actuación en la ciudad determinada: Guadalajara, sede principal de asentamiento de la familia Mendoza.

\begin{abstract}
In light of today's unquestionable interest and historical study of the 16th century, this article focuses on a family of Morisco (Muslim converts to Christianity) artisans - the Orejón family- within a specific locale.

This study shall assess the form of support that certain noble families extended to their Morisco workers to protect them against the daily obstacles they faced within a hostile Christian society.

This work, leaving aside artistic considerations, offers a view on the formation of a "convert kinship" in the context of a specific city, Guadalajara, where the noble Mendoza family resided.
\end{abstract}

